ESTUDOS REEP

\title{
As parcerias público-privadas para a oferta de vagas na educação infantil: um estudo em municípios paulistas
}

Raquel Fontes Borghi

Theresa Adrião

Teise Garcia

\section{Resumo}

Apresenta resultados de pesquisa que teve por objetivo analisar a natureza e as consequências de parcerias firmadas entre o poder público municipal e as instituições privadas de educação infantil. Foram realizados estudos de caso em sete municípios do Estado de São Paulo, com parcerias em vigência no período de 1997 a 2006. A partir dos estudos de caso foi possível identificar regularidades e diferenças no que se refere a: implicações da parceria para a normalização e instâncias decisórias no âmbito da política municipal; alterações na organização da administração municipal; gastos efetuados pelos municípios; e indicadores educacionais. Os resultados evidenciaram uma diferenciação entre os tradicionais convênios e as novas parcerias que são realizadas, principalmente, com instituições privadas stricto sensu.

Palavras-chave: parcerias; público-privado; educação infantil. 


\section{Abstract \\ Public-private partnerships to the supply of vacancies in early childhood education: a study in some cities in São Paulo}

This paper presents the results of a research that aimed at the nature and the consequences of the partnerships among the municipal government and private early childhood education institutions. There were case studies in seven municipalities of São Paulo state concerning partnerships that were actives from 1997 to 2006. This made possible to identify regularities and differences in the process of partnership normalization as well as the municipal policies decisory instances; alterations in the municipal administration organization; municipal expenses and educational indicators. The results evidenced a differentiation among the traditional arrangements and the new partnerships, especially with private institutions.

Keywords: partnerships; public-private; early childhood education.

\section{Introdução}

Este artigo traz resultados de pesquisa interinstitucional ${ }^{1}$ que, além de outras modalidades de parcerias ${ }^{2}$ entre os setores público e privado na educação, investigou aquelas voltadas ao atendimento das demandas por oferta de vagas na educação infantil, em vigência no período de 1997 a 2006 , correspondentes ao Fundo de Manutenção e Desenvolvimento do Ensino Fundamental e de Valorização do Magistério (Fundef). Para a pesquisa foram realizados estudos de caso em sete municípios selecionados, considerando-se o conjunto de municípios pequenos (de 10.001 a 50.000 hab.), médios (de 50.001 a 100.000 hab.), grandes (de 100.001 a 500.000 hab.), muito grandes (de 500.001 a 1.000.000 hab.) e metropolitano (mais que 1 milhão de hab.). O Quadro 1 identifica os municípios participantes da pesquisa.

\section{Quadro 1 - Municípios participantes da pesquisa}

\begin{tabular}{|l|l|}
\hline \multicolumn{1}{|c|}{ Tamanho (Censo 2000) } & \multicolumn{1}{c|}{ Município } \\
\hline Pequenos & Altinópolis e Itirapina \\
\hline Médios & Pirassununga \\
\hline Grandes & Hortolândia e Piracicaba \\
\hline Muito grandes & Ribeirão Preto \\
\hline Metropolitano & São Paulo \\
\hline
\end{tabular}

\footnotetext{
${ }^{1}$ Pesquisa "Estratégias municipais para a oferta da educação básica: análise de parcerias público-privadas no Estado de São Paulo", financiada pela Fundação de Amparo à Pesquisa do Estado de São Paulo (Fapesp).

${ }^{2}$ Designamos parceria os acordos formalmente firmados pelo poder público com setores da iniciativa privada, entendendo, como Bezerra (2008, p. 62-63), que a expressão parceria público-privada "[...] implica também na capacidade de intervenção que o setor privado passa a dispor junto à administração pública, por meio da assunção total ou parcial de responsabilidades até então atribuídas ao poder público em sua totalidade"
} 
Nos casos em análise, foram realizadas entrevistas com os dirigentes municipais de educação e com os representantes do governo municipal envolvidos no processo de parceria, conforme se julgou necessário. Foram coletados documentos referentes aos convênios/parcerias e à educação no município, bem como balanços que possibilitassem uma análise dos recursos financeiros envolvidos nas parcerias. Na coleta dos dados financeiros é que se localizaram as maiores dificuldades do estudo, considerando-se a falta de informações, o difícil acesso aos balanços e aos termos de convênio.

O Quadro 2 apresenta o número de instituições privadas parceiras em cada município pesquisado, assim como o tipo de instituição privada conveniada, apresentando uma caracterização inicial das parcerias.

Quadro 2 - Características gerais da parceria nos municípios pesquisados

\begin{tabular}{|c|c|c|c|}
\hline Municípios & Início do convênio & $\begin{array}{c}\text { Tipo de } \\
\text { instituição } \\
\text { privada } \\
\text { conveniada }\end{array}$ & $\begin{array}{l}\text { Número de instituições } \\
\text { conveniadas }\end{array}$ \\
\hline Altinópolis & $\begin{array}{l}\text { Anterior ao período de } \\
\text { vigência do Fundef e já } \\
\text { finalizado. }\end{array}$ & $\begin{array}{l}\text { Sem fins } \\
\text { lucrativos. }\end{array}$ & 1 (convênio já finalizado). \\
\hline Itirapina & $\begin{array}{l}\text { Anterior ao período } \\
\text { de vigência do Fundef, } \\
\text { mas primeiro convênio } \\
\text { assinado em } 2000 \text { com } \\
\text { a Secretaria Municipal } \\
\text { de Educação. }\end{array}$ & $\begin{array}{l}\text { Sem fins } \\
\text { lucrativos. }\end{array}$ & $\begin{array}{l}2 \text { (informação correspon- } \\
\text { dente ao ano final do período } \\
\text { de estudo, 2006). }\end{array}$ \\
\hline Pirassununga & $\begin{array}{l}\text { Em 2003, com duração } \\
\text { de apenas um ano. }\end{array}$ & $\begin{array}{l}\text { Sem fins } \\
\text { lucrativos. }\end{array}$ & 1 (convênio já finalizado). \\
\hline Hortolândia & Em 2005. & $\begin{array}{l}\text { Com e sem } \\
\text { fins lucrati- } \\
\text { vos. }\end{array}$ & $\begin{array}{l}9 \text { (sendo } 1 \text { filantrópica e } 8 \\
\text { stricto sensu - informação } \\
\text { correspondente ao ano final } \\
\text { do período de estudo, 2006). }\end{array}$ \\
\hline Piracicaba & Em 2001. & $\begin{array}{l}\text { Com e sem } \\
\text { fins lucrati- } \\
\text { vos. }\end{array}$ & $\begin{array}{l}42 \text { (sendo } 10 \text { filantrópicas e } \\
32 \text { stricto sensu - informa- } \\
\text { ção correspondente ao ano } \\
\text { final do período de estudo, } \\
2006) \text {. }\end{array}$ \\
\hline Ribeirão Preto & $\begin{array}{l}\text { Anterior ao período de } \\
\text { vigência do Fundef e } \\
\text { início em 1999, com a } \\
\text { Secretaria Municipal } \\
\text { de Educação. }\end{array}$ & $\begin{array}{l}\text { Sem fins } \\
\text { lucrativos. }\end{array}$ & $\begin{array}{l}18 \text { (informação correspon- } \\
\text { dente ao ano final do período } \\
\text { de estudo, 2006). }\end{array}$ \\
\hline São Paulo & $\begin{array}{l}\text { Anterior ao período de } \\
\text { vigência do Fundef. }\end{array}$ & $\begin{array}{l}\text { Entidades, } \\
\text { associações } \\
\text { e organiza- } \\
\text { ções sem fins } \\
\text { lucrativos. }\end{array}$ & $\begin{array}{l}664 \text { creches particulares } \\
\text { conveniadas (informação } \\
\text { retirada do site da Secretaria } \\
\text { Municipal de Educação no } \\
\text { ano de 2009). }\end{array}$ \\
\hline
\end{tabular}

Fonte: Elaboração própria, com base nos estudos de caso realizados. 
No Quadro 2, o que mais chama a atenção são os novos arranjos que vêm se firmando para além da tradicional subvenção às instituições privadas sem fins lucrativos. Os municípios que adotaram o Programa Bolsa Creche - Hortolândia e Piracicaba - fazem convênios com instituições privadas com fins lucrativos, subsidiando-as a partir de um valor per capita. Nos demais municípios, as instituições privadas conveniadas são consideradas sem fins lucrativos, podendo ser filantrópicas, confessionais ou comunitárias.

\section{Regularidades e diferenças em relação às implicações das parcerias}

Discute-se aqui as regularidades e diferenças encontradas nos casos pesquisados. Por regularidades consideramos características que se apresentam comuns nos diferentes municípios, o que poderia nos indicar algumas tendências mais gerais nos formatos de parceria. A fim de verificar tais aspectos, a análise toma por referência quatro indicadores: o primeiro refere-se às implicações da parceria para a normalização e instâncias decisórias no âmbito da política municipal; a seguir, identificam-se as alterações na organização da administração municipal tendo em vista a implantação dos convênios; em um terceiro momento, comparam-se os gastos efetuados pelos municípios; e, por fim, é analisada a evolução das matrículas municipais e privadas.

\section{Normalização e lócus decisório no âmbito da política municipal}

Este item compara as formas por meio das quais são regulamentadas as parcerias nos municípios pesquisados, bem como o lócus decisório para sua implantação. Além da realização de entrevistas com gestores locais, foram analisados documentos legais produzidos em cada administração no que diz respeito às diretrizes educacionais, planos municipais de educação, legislações referentes ao conselho municipal de educação, conselhos de escola e outras leis.

Em relação à forma de normalização das parcerias, em todos os municípios pesquisados, o tipo de acordo firmado é o convênio. Isso é decorrente da própria natureza das parcerias na modalidade oferta de vagas. Conforme Silveira (2009), o convênio é um instrumento que tem características próprias e é utilizado pela administração pública para associar-se com entidades públicas ou privadas. A autora explica, baseando-se em Di Pietro (2005), que a principal característica para diferenciar convênio e contrato refere-se aos interesses. No contrato, os interesses são opostos e contraditórios e, no convênio, os interesses institucionais e os resultados são comuns e verifica-se a mútua colaboração.

Di Pietro (2005) afirma que como o convênio tem como pressuposto a mútua colaboração, não se faz necessária a licitação, pois não há competição. Nos municípios pesquisados, não encontramos nenhum 
processo de licitação. A autora também ressalta que a colaboração mútua pode assumir variadas formas, como repasse de verbas, uso de equipamentos, recursos humanos, imóveis e know-how. Essas formas variadas de colaboração mútua ficam evidentes nos casos estudados, como veremos mais adiante.

Em relação às implicações das parcerias para as diretrizes educacionais municipais, fica evidente uma opção do poder público municipal em investir recursos públicos na esfera privada. Há um município (Itirapina) que não possui nenhuma creche municipal para atendimento direto, nos demais municípios, há atendimento direto e conveniado e, em dois municípios com o Programa Bolsa Creche, os repasses são feitos principalmente para instituições privadas stricto sensu com fins lucrativos.

Mais uma vez os municípios com o Programa Bolsa Creche se destacam e fazem uma opção clara pela ampliação da oferta de vagas em creches via instituições privadas com fins lucrativos, evidenciando um novo arranjo institucional entre o público e o privado, que caminha no sentido da privatização dessa etapa de ensino. Domiciano (2009) aponta a falta de respaldo legal na legislação brasileira para a subvenção pública a instituições privadas stricto sensu.

Não há evidências referentes à indução dos convênios/parceria na constituição ou forma de funcionamento dos conselhos de escola, no plano municipal de educação e no conselho municipal de educação. Também não há evidências de que a parceria induziu à publicização de indicadores educacionais.

No que se refere à alteração no lócus decisório da política educacional municipal, não há evidencias de que esse tipo de parceria tenha induções significativas. No entanto, o fato é que, ao transferir para a instituição privada a responsabilidade pela oferta de vagas em creches, são essas instituições que ficam responsáveis pelo trabalho realizado com as crianças, pelas condições de trabalho dos docentes, por políticas de formação, pela organização do trabalho na escola, pela infraestrutura, pela merenda, etc.

Em Itirapina, a parceria não altera o lócus decisório da política educacional municipal. No entanto, em relação à oferta educacional para crianças de 0 a 3 anos, como é a única forma de atendimento, não há creche direta, as decisões e os direcionamentos ficam por conta das instituições privadas. A única forma de regulação do poder público em relação às creches é a aprovação do plano de atividade e a orientação por parte das supervisoras do sistema municipal de educação.

Em Altinópolis, o formato de parceria adotado - oferta de vaga em instituição filantrópica - e, posteriormente, a assunção do atendimento por via direta por parte do poder público, não implicou criação de órgãos decisórios. Também em Pirassununga, as decisões administrativas e pedagógicas eram tomadas pelos representantes da fundação em conjunto com a Secretaria Municipal de Educação (SME).

Nos municípios com o Programa Bolsa Creche (Piracicaba e Hortolândia), o mentor da política educacional é o município, entretanto, este fica sempre condicionado, no caso das vagas via Bolsa Creche, à 
quantidade de vagas oferecidas pela instituição parceira. Nesses dois municípios, há uma regulação mais sistemática por parte do poder público em relação às instituições privadas. Em Piracicaba, por exemplo, as escolas conveniadas devem estar regularizadas junto à prefeitura. A Lei Municipal n 5.081/01 estabelece responsabilidades da instituição privada conveniada. Também há no município uma Instrução Normativa, com normas a serem seguidas pelas escolas conveniadas. Em Hortolândia, que também tem o Programa Bolsa Creche, a Lei Municipal n 1.506/05 prevê as mesmas responsabilidades das instituições privadas que a lei em Piracicaba e acrescenta outras.

Em todos os municípios com parceria para a oferta de vagas por instituições privadas, o que ocorre é que tais instituições passam a ser responsáveis pelo trabalho realizado com as crianças, mas com diferentes graus de regulação por parte do poder público municipal, com destaque para os municípios maiores e para os municípios com o Programa Bolsa Creche, que possuem uma regulação mais sistemática em relação às instituições privadas.

Quanto ao controle social, o que se tem de mais frequente nos municípios estudados são pressões do Ministério Público (MP) pelo atendimento na educação infantil. Para Mizuki e Silveira (2009), em que pese o fato de a subvenção de recursos financeiros às instituições privadas para a oferta de vagas em educação infantil ser uma opção do poder executivo municipal, não se pode deixar de dizer que a pressão pelo atendimento, exercido institucionalmente pelo MP, tem contribuído para o estabelecimento de parcerias, pois esta forma se constitui em um mecanismo mais ágil e barato.

Implicações para a organização administrativa da rede municipal

Neste item, o objetivo foi identificar se a implantação da parceria trouxe alterações na organização administrativa e no quadro de funcionários das redes municipais. Para tanto, foi considerado se, no período estabelecido nesta pesquisa (1997-2006), houve a criação/implantação de novo setor ou pessoa responsável pela parceria na SME, implantação de plano de carreira e alterações no número de funções docentes.

Em relação às alterações referentes à introdução de novo setor/ pessoa responsável pela parceria/convênio, nota-se mais uma vez uma diferenciação entre os convênios tradicionais e os municípios com o Programa Bolsa Creche. Nos municípios com os convênios tradicionais, não houve a criação de um setor para o acompanhamento dos convênios. Nos dois municípios muito pequenos e pequenos, há apenas a supervisão das instituições conveniadas pela equipe responsável. Em Ribeirão Preto, município grande e com convênio tradicional, o que houve foi o aumento de funções para os setores/pessoas já existentes da rede e a atuação do conselho municipal de educação na emissão de pareceres sobre a assistência do município a instituições de ensino filantrópicas, 
comunitárias e confessionais. Em São Paulo, com a implantação de 31 subprefeituras, as 13 Divisões Regionais de Educação (DREs) ficaram responsáveis pelo acompanhamento dos convênios, uma vez que, anteriormente, eram realizados pelo setor de convênios, localizado na assessoria técnica de planejamento junto ao gabinete da SME. Já nos dois municípios que possuem o Programa Bolsa Creche, foram criados novos departamentos.

Quanto aos planos de carreira, o objetivo foi identificar se existiam referências aos profissionais da educação das instituições conveniadas. O município de Hortolândia foi o único em que havia referências às instituições conveniadas no plano de carreira. A Lei Municipal n 2.164/08, que dispõe sobre a organização do magistério e dá outras providências, estabelece que as atividades do magistério podem ser exercidas em entidades conveniadas, sem prejuízo de remuneração e demais vantagens e direitos do cargo.

Nos municípios de Altinópolis, Itirapina e Ribeirão Preto, há plano de carreira, mas esses não fazem menção aos profissionais das creches conveniadas. São Paulo também possui plano de carreira, no entanto, ele é exclusivo para os profissionais da rede direta. Nos municípios de Piracicaba e Pirassununga não há plano de carreira aprovado.

A análise das funções docentes nos municípios pesquisados teve por objetivo identificar possíveis alterações entre as esferas pública e privada após a implantação da parceria/convênio. No entanto, nos dados coletados pelo Instituto Nacional de Estudos e Pesquisas Educacionais Anísio Teixeira (Inep) existem muitas discrepâncias que impedem uma análise consistente. Ainda assim, o que se pôde perceber foi que na rede privada de municípios pequenos não havia funções docentes, o que pode indicar que o atendimento em creches seja realizado por monitoras. ${ }^{3}$

As Tabelas 1 a 7 trazem os dados sobre funções docentes em creches nas redes municipal e privada.

Tabela 1 - Número de funções docentes em creches municipais e privadas Altinópolis - 1999-2006

\begin{tabular}{|l|c|c|c|c|c|c|c|c|}
\hline $\begin{array}{l}\text { Rede de } \\
\text { ensino }\end{array}$ & 1999 & 2000 & 2001 & 2002 & 2003 & 2004 & 2005 & 2006 \\
\hline Municipal & 2 & 0 & 0 & 0 & 0 & 0 & 0 & 0 \\
\hline $\begin{array}{l}\text { Privada } \\
\text { Fonte: < http//www_edudatabrasil inep gov br/> }\end{array}$ & 0 & 9 & 4 & 0 & 1 & 0 & 0 & 0 \\
\hline
\end{tabular}

Tabela 2 - Número de funções docentes em creches municipais e privadas Itirapina - 1999-2006

${ }^{3}$ Monitoras são profissionais que trabalham com as crianças principalmente no que se refere aos cuidados. Não há exigência legal de formação para o magistério.

\begin{tabular}{|c|c|c|c|c|c|c|c|c|}
\hline $\begin{array}{l}\text { Rede de } \\
\text { ensino }\end{array}$ & 1999 & 2000 & 2001 & 2002 & 2003 & 2004 & 2005 & 2006 \\
\hline Municipal $^{(1)}$ & - & - & - & - & - & - & - & - \\
\hline Privada & 0 & 0 & 1 & 0 & 0 & 0 & 0 & 0 \\
\hline
\end{tabular}


Em Itirapina, como visto anteriormente, não há creches diretas no município. A Tabela 2 evidencia que as creches conveniadas - única opção no município - não possuem professores e trabalham exclusivamente com "monitores".

Em Pirassununga, os dados mostram um decréscimo no número de funções docentes na rede municipal entre 2001 e 2006 e uma ampliação na rede privada.

Tabela 3 - Número de funções docentes em creches municipais e privadas Pirassununga - 1999-2006

\begin{tabular}{|l|c|c|c|c|c|c|c|c|}
\hline $\begin{array}{l}\text { Rede de } \\
\text { ensino }\end{array}$ & 1999 & 2000 & 2001 & 2002 & 2003 & 2004 & 2005 & 2006 \\
\hline Municipal & 0 & 0 & 25 & 9 & 9 & 10 & 12 & 13 \\
\hline Privada & 5 & 5 & 9 & 14 & 15 & 14 & 18 & 16 \\
\hline
\end{tabular}

Fonte: <http://www.edudatabrasil.inep.gov.br/>.

Em Hortolândia, há um aumento considerável nas funções docentes da esfera municipal no período analisado e um número bastante reduzido na rede privada. Somente a partir de 2004 é que aparecem funções docentes na rede privada e, mesmo assim, em quantidade mínima. Tal fato pode ser explicado, pois foi a partir desse ano que as instituições privadas passaram a se regularizar no município como exigência para se candidatarem aos convênios. O baixo número de funções docentes também pode indicar que a maior parte das instituições privadas trabalha apenas com monitores para o atendimento à criança.

Tabela 4 - Número de funções docentes em creches municipais e privadas Hortolândia - 1999-2006

\begin{tabular}{|l|c|c|c|c|c|c|c|c|}
\hline $\begin{array}{l}\text { Rede de } \\
\text { ensino }\end{array}$ & 1999 & 2000 & 2001 & 2002 & 2003 & 2004 & 2005 & 2006 \\
\hline Municipal & 0 & 2 & 1 & 16 & 34 & 46 & 49 & 50 \\
\hline Privada & 0 & 0 & 0 & 0 & 0 & 3 & 4 & 2 \\
\hline
\end{tabular}

Fonte: <http://www.edudatabrasil.inep.gov.br/>.

Em Piracicaba, os números na rede municipal são descontínuos e impedem qualquer análise. Já na rede privada, há um crescimento considerável de funções docentes no período.

Tabela 5 - Número de funções docentes em creches municipais e privadas Piracicaba - 1999-2006

\begin{tabular}{|l|c|c|c|c|c|c|c|c|}
\hline $\begin{array}{l}\text { Rede de } \\
\text { ensino }\end{array}$ & 1999 & 2000 & 2001 & 2002 & 2003 & 2004 & 2005 & 2006 \\
\hline Municipal & 68 & 0 & 2 & 0 & 1 & 68 & 85 & 155 \\
\hline Privada & 83 & 118 & 131 & 138 & 167 & 180 & 181 & 229 \\
\hline
\end{tabular}

Fonte: <http://www.edudatabrasil.inep.gov.br/>.

Em Ribeirão Preto, a evolução das funções docentes se dá nas duas redes (municipal e privada) e acompanha a evolução das matrículas. 
Tabela 6 - Número de funções docentes em creches municipais e privadas Ribeirão Preto - 1999-2006

\begin{tabular}{|l|c|c|c|c|c|c|c|c|}
\hline $\begin{array}{l}\text { Rede de } \\
\text { ensino }\end{array}$ & 1999 & 2000 & 2001 & 2002 & 2003 & 2004 & 2005 & 2006 \\
\hline Municipal & 144 & 171 & 177 & 198 & 223 & 166 & 175 & 223 \\
\hline Privada & 88 & 102 & 126 & 189 & 160 & 222 & 245 & 256 \\
\hline
\end{tabular}

Fonte: <http://www.edudatabrasil.inep.gov.br/>.

Por fim, São Paulo tem dados descontínuos na rede municipal até 2002 e, nos anos seguintes, há um crescimento das funções docentes nesta rede. Já em relação à rede privada, há um considerável crescimento no período.

Tabela 7 - Número de funções docentes em creches municipais e privadas São Paulo - 1999-2006

\begin{tabular}{|c|c|c|c|c|c|c|c|c|}
\hline $\begin{array}{l}\text { Rede de } \\
\text { ensino }\end{array}$ & 1999 & 2000 & 2001 & 2002 & 2003 & 2004 & 2005 & 2006 \\
\hline $\begin{array}{l}\text { Municipal } \\
\text { Privada }\end{array}$ & 717 & 5 & 2 & 61 & 502 & 2.222 & 3.483 & 5.687 \\
\hline Prive & 2.477 & 1.961 & 2.091 & 3.011 & 3.435 & 4.845 & 4.614 & 3.693 \\
\hline
\end{tabular}

Fonte: <http://www.edudatabrasil.inep.gov.br/>.

O que se pode perceber é uma tendência em instituições privadas de municípios pequenos que o atendimento em creches seja realizado por monitoras. Nos municípios maiores - Piracicaba, Ribeirão Preto e São Paulo -, tal tendência não se verifica na análise da evolução das funções docentes em creches nas redes municipal e privada.

\section{Gastos com a parceria}

Na análise dos gastos com a parceria foram considerados: o formato de subsídio do poder público municipal às instituições privadas conveniadas; o gasto por aluno em instituições diretas e em instituições conveniadas; e o percentual gasto pelo município com as parcerias/convênios em relação ao total de gastos com a educação infantil.

No que se refere ao formato de financiamento, encontramos nos casos pesquisados uma diferenciação. Em Altinópolis, não conseguimos informações para a análise financeira das parcerias/convênios.

Em Itirapina, o repasse de recursos do convênio assinado entre o poder público municipal e a instituição privada conveniada se dá a partir de um plano de atividades apresentado por esta última e que contenha uma planilha dos gastos que deverão ser cobertos pelo convênio. Neste município, o convênio cobre os gastos das instituições privadas com o pagamento de funcionários e cabe ao município examinar as prestações de contas das instituições privadas conveniadas. Somente em 2000 é que foi assinado o primeiro convênio com essas características, antes disso, o que ocorria era uma cooperação da prefeitura com a merenda e a cessão de funcionários municipais para as duas entidades filantrópicas. Em Pirassununga, o valor repassado era correspondente ao total de gastos da instituição para a manutenção da creche. 
Nos municípios com o Programa Bolsa Creche (Hortolândia e Piracicaba), o repasse de recursos se dá em função de um valor por aluno/ mês, com valores diferenciados para os turnos parcial e integral.

Em Ribeirão Preto e São Paulo, o repasse é vinculado ao número de matrículas da instituição. Em São Paulo, há valores diferentes conforme o número de alunos atendidos pela instituição, quanto maior o número de alunos atendidos, menor o valor repassado por aluno. O que se percebe é uma crescente opção por repasse de recursos vinculados ao número de matrículas.

A comparação entre os gastos municipais com creches diretas e conveniadas, a partir dos dados obtidos nos estudos de casos, foi limitada a três municípios (Itirapina, Hortolândia e Piracicaba), pois não foi possível obter os dados para Altinópolis, Ribeirão Preto e São Paulo, e para Itirapina, que não possui creches municipais, só apresentamos os gastos com as instituições conveniadas. Todavia, as informações que foram conseguidas tornaram possível verificar uma grande disparidade nos valores gastos com as instituições diretas de educação infantil municipais e com as instituições privadas conveniadas. ${ }^{4}$

A Tabela 8 apresenta os gastos municipais por aluno nas instituições conveniadas de Itirapina. Os totais foram constituídos considerando-se o valor repassado pela prefeitura a duas instituições privadas conveniadas, dividido pelo total de alunos por elas atendidos.

\begin{tabular}{|c|c|c|c|c|c|}
\hline & 2002 & 2003 & 2004 & 2005 & 2006 \\
\hline $\begin{array}{l}\text { Valor per } \\
\text { capita/ano }\end{array}$ & 759,01 & 644,83 & 814,17 & 741,29 & 865,38 \\
\hline
\end{tabular}

Fonte: Souza (2009) - composta com base em valores dos convênios e número de alunos conveniados.

Em Pirassununga, o valor gasto por aluno municipal é menor do que o gasto por aluno da instituição conveniada (Gráfico 1).

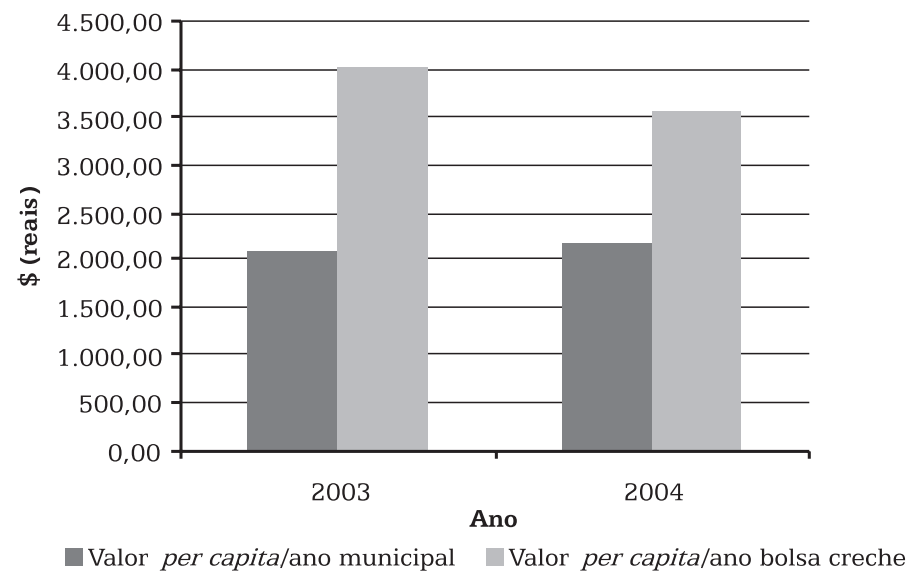

Gráfico 1 - Valor gasto pelo poder público municipal por aluno matriculado nas instituições de educação infantil diretas e conveniadas - Pirassununga $2003 / 2004$

Fonte: Bezerra (2008) - valores compostos a partir dos gastos com os convênios e o número de alunos atendidos pela instituição conveniada.
4 Os valores estão indexados
pelo Índice Nacional de Preço ao
Consumidor (INPC) para dezemConsumidor
bro de 2008 . 
Já em Piracicaba e Hortolândia - municípios que adotaram o Programa Bolsa Creche -, é nítida a economia municipal com a adoção do programa. O valor per capita destinado às instituições privadas conveniadas é bem menor que o valor gasto na rede municipal (Gráficos 2 e 3).

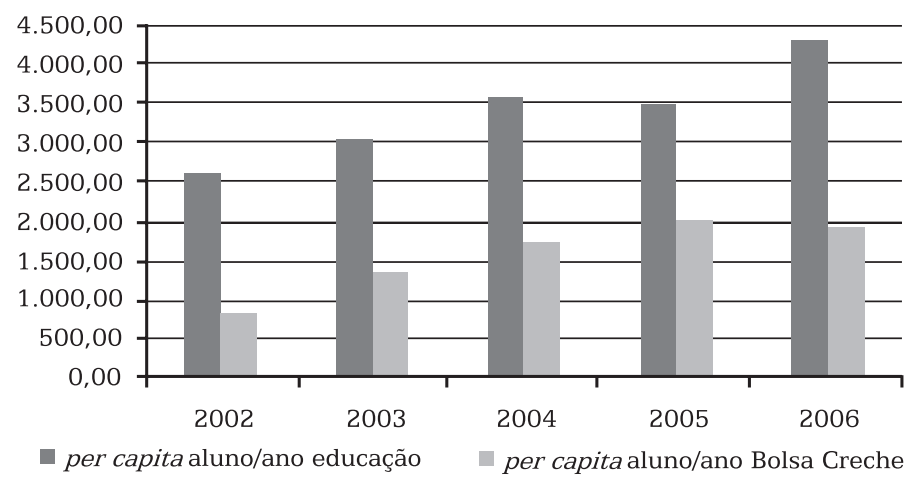

Gráfico 2 - Valor gasto pelo poder público municipal por aluno matriculado nas instituições de educação infantil diretas e conveniadas Piracicaba - 2002-2006

Fonte: Domiciano (2009) com base em: Piracicaba. Secretaria Geral de Finanças. Balancete das despesas (2002 a 2006); Relatório das despesas com Bolsa Creche (2002 a 2004)

Observação: Valores em reais

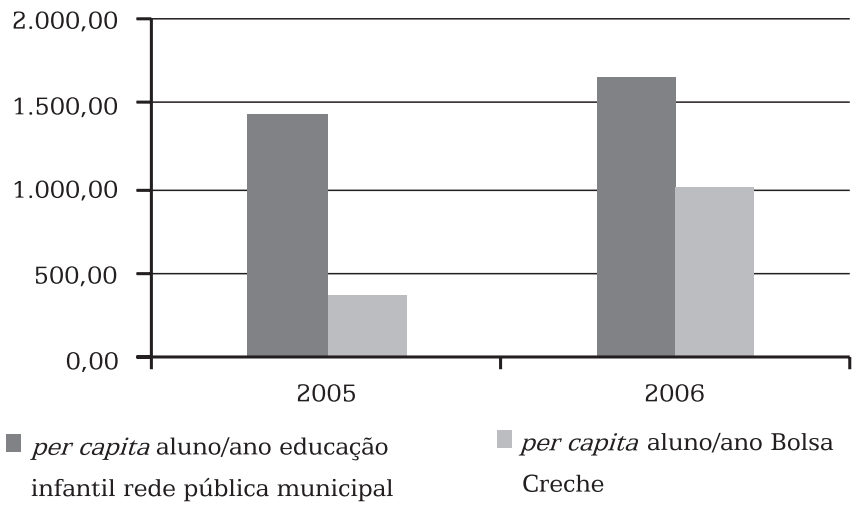

Gráfico 3 - Valor gasto pelo poder público municipal por aluno matriculado nas instituições de educação infantil diretas e conveniadas Hortolândia - 2005-2006

Fonte: Hortolândia. Secretaria Municipal de Finanças. Balancete das despesas (2005 a 2006).

Observação: Valores em reais.

Conforme Domiciano (2009), a preocupação em oferecer a educação infantil a um custo reduzido implica na qualidade do serviço prestado. Nesses dois municípios, o objetivo de redução de custos se efetiva. É importante ressaltar que em Hortolândia e Piracicaba a autora relata que não há exigências de prestação de contas para as instituições conveniadas. Outro ponto a ser destacado em relação a esses dois municípios é que os valores per capita fixados eram os mesmos para a etapa da creche e da 
pré-escola. Para Domiciano (2009), considerando-se que o custo de um aluno em creche é maior que o custo na pré-escola, a falta de diferenciação no subsídio público às instituições conveniadas pode direcionar a atuação de tais instituições na etapa economicamente mais viável.

Quanto à porcentagem gasta pelos municípios na parceria em relação ao gasto municipal total na educação infantil, ${ }^{5}$ os dados evidenciam também uma multiplicidade de situações.

Em Itirapina, tivemos acesso aos dados financeiros gastos com a parceria apenas a partir de 2002, apesar de a parceria/convênio ser mais antiga. Nesse ano, a porcentagem gasta com a parceria em relação ao total gasto com a educação infantil no município foi de 52,28\%. Em 2006, esse percentual diminuiu para $26,78 \%$.

Em Pirassununga, os gastos com a parceria em relação ao total gasto com a educação infantil foram de 6,89\% e 5,72\% respectivamente para os anos de 2003 e 2004 - período de vigência do convênio.

Já em Hortolândia, em 2005, ano inicial do Programa Bolsa Creche, a porcentagem foi de 0,62\% e, no ano seguinte, 4,50\% em relação ao total gasto com a educação infantil.

Em Piracicaba, em 2002, primeiro ano de vigência do convênio, a porcentagem gasta foi de 4,19\% em relação ao total gasto com a educação infantil e, em 2006, ano final do período de estudo, a porcentagem já era de $26,57 \%$.

Quanto à Altinópolis, Ribeirão Preto e São Paulo, não tivemos acesso aos gastos com as parcerias/convênios.

A Tabela 9 facilita a visualização do percentual gasto com a parceria em relação ao total gasto pelo município com a educação infantil. Para Itirapina, consideramos o ano de 2002 e 2006. O primeiro, por não termos tido acesso aos anos anteriores a 2002 e o segundo, 2006, corresponde ao ano final do período do nosso estudo. Para Pirassununga, foram considerados os anos inicial e final da parceria/convênio - 2003/2004. Já em Hortolândia e Piracicaba, foi considerado o ano inicial do Programa Bolsa Creche e 2006, ano final do período do estudo.

Tabela 9 - Percentual gasto com a parceria em relação ao total gasto pelo município com a educação infantil

\begin{tabular}{|c|c|c|}
\hline Município & Ano e percentual & Ano e percentual \\
\hline \multirow{2}{*}{ Itirapina } & 2002 & 2006 \\
\hline \multirow{2}{*}{ Pirassununga } & $52,28 \%$ & $26,78 \%$ \\
\hline \multirow{2}{*}{ Hortolândia } & 2003 & 2004 \\
\hline \multirow{2}{*}{ Piracicaba } & $6,89 \%$ & $5,72 \%$ \\
\hline & 2005 & 2006 \\
\hline
\end{tabular}

Fonte: Itirapina. Termos de convênio (2002-2006). Pirassununga: Bezerra (2009). Piracicaba. Secretaria Geral de Finanças. Balancete das despesas (2002 e 2006); Relatório das despesas com Bolsa Creche (2002 a 2004); Hortolândia. Secretaria Municipal de Finanças. Balancete das despesas (2005 a 2006).
5 Para a comparação foram retirados dos gastos totais com a educação infantil os gastos realizados com a parceria/convênio. 
O que se pode perceber, a partir dos dados da Tabela 9, é que nos dois municípios que adotaram o Programa Bolsa Creche (Piracicaba e Hortolândia) há um aumento da porcentagem gasta com a parceria/ convênio nos dois anos em destaque. Já nos demais municípios, há um decréscimo da porcentagem no período considerado.

\section{Evolução das matrículas de educação infantil nos municípios pesquisados}

Neste item a intenção foi analisar a evolução das matrículas em creches nos municípios da amostra com o objetivo de identificar possíveis implicações e tendências a partir da adoção das parcerias/convênios. Para tanto, o período considerado inicialmente seria o da pesquisa (1997-2006), no entanto, só foram encontrados dados para matrículas em creches a partir do ano de 1999. Foram consideradas as matrículas da rede pública municipal e da rede privada e, em alguns casos, as matrículas conveniadas.

A partir da análise das matrículas foi possível perceber que nos municípios pequenos, ao longo do período estudado, não há uma ampliação considerável em relação à oferta educacional para a criança de 0 a 3 anos. Considerando-se que o período equivale à vigência do Fundef, a focalização de recursos no ensino fundamental e o processo de municipalização parecem ter influenciado negativamente a educação infantil.

Nos municípios maiores - Ribeirão Preto e São Paulo - o crescimento se dá tanto nas matrículas públicas como nas privadas, sejam elas stricto sensu ou conveniadas.

Já em relação aos municípios com um novo formato de parceria/ convênio, quais sejam, os que adotaram o Programa Bolsa Creche Hortolândia e Piracicaba -, há uma clara contenção das matrículas públicas e um avanço considerável nas matrículas privadas conveniadas, com e sem fins lucrativos. Tal evidência revela uma clara política municipal de investimento público na educação infantil privada. Para Domiciano (2009), o programa se difere dos tradicionais formatos de convênios instituídos na educação infantil com entidades filantrópicas e/ou assistenciais e acentua seu caráter privatizante. Também para esta autora, a parceria constitui-se em um campo "lucrativo" e "seguro" para as escolas privadas se manterem no mercado educacional.

Quanto à contabilização das matrículas conveniadas, também foi possível verificar uma multiplicidade de situações. Em Itirapina, elas são contabilizadas como matrículas privadas e, em Altinópolis, Pirassununga e Ribeirão Preto, não foi possível precisar onde elas são contabilizadas. Em Hortolândia, até 2006, elas não estavam no cômputo municipal nem no privado e, em Piracicaba, as matrículas conveniadas foram, até 2006, contabilizadas como privadas e, a partir de então, transferidas e contadas como públicas. Para Domiciano (2009), há pelo menos dois problemas nessa situação: o primeiro refere-se ao repasse indevido de recursos do Fundo de Manutenção e Desenvolvimento da Educação Básica e de 
Valorização dos Profissionais da Educação (Fundeb) às escolas conveniadas privadas em sentido estrito; e o segundo liga-se às imprecisões existentes nos dados oficiais de matrículas públicas e privadas, gerando a falsa ideia de que a expansão do atendimento à educação infantil tenha se dado na esfera pública estatal.

\section{Algumas considerações}

Os estudos de caso evidenciaram uma diferenciação entre os tradicionais convênios realizados entre o poder público municipal e as instituições privadas sem fins lucrativos e as novas parcerias que são realizadas, principalmente, com instituições privadas stricto sensu. Dos sete casos da amostra, dois são parcerias/convênios recentes, em que os subsídios não se restringem a instituições sem fins lucrativos.

A criação do Fundeb deverá contribuir para a consolidação da tradição de convênios e parcerias entre o setor público e o privado na oferta de educação infantil, ainda que tenha resgatado o conceito de educação básica como um direito, uma vez que nele estão incluídas todas as etapas e modalidades de ensino. Isso porque a Emenda Constitucional no 53/2006 incluiu as matrículas da educação infantil e da educação especial, inclusive da rede conveniada sem fins lucrativos. Arelaro (2008), aponta que este Fundo incentiva a política de ampliação de vagas por convênios, não só quando permite o repasse de recursos do Fundo para as instituições privadas sem fins lucrativos, mas também quando estabelece um coeficiente para creches e pré-escolas abaixo do valor das séries iniciais urbanas de ensino fundamental. Para ela, esta subvalorização dos custos operacionais das creches e pré-escolas pressupõe que os municípios busquem alternativas menos onerosas para dar conta da grande pressão de demanda desta etapa de ensino (Arelaro, 2008, p. 60). Para a autora, é de se supor que a busca pela manutenção e expansão das parcerias firmadas com o setor privado sejam consolidadas.

Novos estudos devem ser realizados acerca das implicações do Fundeb para o atendimento em instituições conveniadas de educação infantil. O caso de Piracicaba evidenciou que formas de burlar a restrição aos subsídios às instituições privadas sem fins lucrativos já vêm sendo colocadas em prática, como a contabilização de matrículas de instituições conveniadas com fins lucrativos como sendo matrículas públicas.

\section{Referências bibliográficas}

ADRIÃO, Theresa Maria de Freitas et al. Estratégias municipais para a oferta da educação básica: análise de parcerias público-privadas no Estado de São Paulo - relatório de pesquisa. Brasília: Fapesp, 2009. 
ADRIÃO, Theresa Maria de Freitas; BORGHI, Raquel Fontes. Parcerias entre prefeituras e esfera privada: estratégias privatizantes para a oferta da educação pública em São Paulo? In: ADRIÃO, Theresa Maria de Freitas; PERONI, Vera Maria Vidal (Orgs.). Público e privado na educação: novos elementos para o debate. São Paulo: Xamã, 2008. p. 101-110.

ARELARO, Lisete Regina Gomes. A não-transparência nas relações público-privadas: o caso das creches conveniadas. In: ADRIÃO, Theresa Maria de Freitas; PERONI, Vera Maria Vidal (Orgs.). Público e privado na educação: novos elementos para o debate. São Paulo: Xamã, 2008. p. 51-66.

BALL, Stephen J. Performatividade, privatização e o pós-Estado do Bem-Estar. Educação \& Sociedade, Campinas, v. 25, n. 89, p. 1105-1126, set./dez. 2004. Disponível em:

$<$ http://www.scielo.br/scielo.php?script = sci_issuetoc\&pid $=0101$ $733020040004 \& \operatorname{lng}=$ pt\&nrm $=$ iso $>$.

BEZERRA, Egle Pessoa. Parceria público-privada nos municípios de Brotas e Pirassununga: estratégias para a oferta do ensino? $181 \mathrm{f}$. 2008. Dissertação (Mestrado em Políticas e Gestão de Organizações Educacionais) - Universidade Estadual Paulista (Unesp), Rio Claro, 2008.

BRASIL. Emenda Constitucional no 53, de 19 de dezembro de 2006. Dá nova redação aos arts. 7º 23, 30, 206, 208, 211 e 212 da Constituição Federal e ao art. 60 do Ato das Disposições Constitucionais Transitórias. Disponível em: < http://www.planalto.gov. br/ccivil_03/constituicao/emendas/emc/emc53.htm>.

. Lei no 8.666, de 21 de junho de 1993. Regulamenta o art. 37, inciso XXI, da Constituição Federal, institui normas para licitações e contratos da Administração Pública e dá outras providências. Diário Oficial da União, Brasília, DF, 22 jun. 1993. Disponível em: <http://www.planalto.gov.br/ccivil_03/Leis/L8666cons.htm>.

Lei no 9.394, de 20 de dezembro de 1996. Estabelece as diretrizes e bases da educação nacional. Diário Oficial da União, Brasília, DF, 23 dez. 1996. Disponível em: < http://www.planalto.gov.br/ ccivil_03/Leis/L9394.htm>.

Lei no 9.424, de 24 de dezembro de 1996. Dispõe sobre o Fundo de Manutenção e Desenvolvimento do Ensino Fundamental e de Valorização do Magistério, na forma prevista no art. 60, § $7^{\circ}$, do Ato das Disposições Constitucionais Transitórias. Diário Oficial da União, Brasília, DF, 26 dez. 1996. Disponível em: < http://www.planalto.gov.br/ ccivil_03/LEIS/L9424compilado.htm>. 
BRASIL. Lei Complementar no 101, de 4 de maio de 2000. Estabelece normas de finanças públicas voltadas para a responsabilidade na gestão fiscal e dá outras providências. Diário Oficial da União, Brasília, DF, 5 maio 2000. Disponível em: <http://www.planalto.gov.br/ccivil_03/Leis/ LCP/Lcp101.htm>.

BRASIL. Presidência da República. Plano Diretor da Reforma do Aparelho do Estado. Brasília, 1995.

COSTA, Márcio da. Criar o público não estatal ou tornar público o estatal? In: ADRIÃO, Theresa Maria de Freitas; PERONI, Vera Maria Vidal (Orgs.). O público e o privado na educação: interfaces entre Estado e Sociedade. São Paulo: Xamã, 2005. p. 13-30.

DI PIETRO, Maria Sylvia Z. Parcerias na administração pública: concessão, permissão, franquia, terceirização, parceria público-privada e outras. São Paulo: Atlas, 2005.

Reflexões sobre as parcerias público-privadas. Disponível em: $<$ http://www.azevedosette.com.br/ppp/artigos/reflexoes.html>. Acesso em: 20 dez. 2008.

DOMICIANO, Cássia Alessandra. O Programa Bolsa Creche: um estudo comparativo dos municípios paulistas de Hortolândia e Piracicaba: uma proposta para alocação de recursos estatais à Educação privada? 228 f. 2009. Dissertação (Mestrado em Educação) - Universidade Estadual Paulista, Rio Claro, 2009. Disponível em: < http://www.athena. biblioteca.unesp.br/exlibris/bd/brc/33004137064P2/2009/domiciano_ ca_me_rcla.pdf $>$.

HORTOLÂNDIA Lei no 1.506, de 28 de julho de 2005. Autoriza o município de Hortolândia a firmar convênio com entidades filantrópicas, ONGs e escolas particulares de educação infantil, objetivando o aumento da oferta de vagas, com a concessão de "bolsas creches" às crianças que não obtenham vagas na rede municipal e dá outras providências.

MIZUKI, Vitor; SILVEIRA, Adriana Aparecida D. Parcerias entre os municípios paulistas e a esfera privada para a oferta de vagas na educação infantil: influência da atuação do Ministério Público local? In: CONGRESSO INTERAMERICANO DE POLÍTICA E ADMINISTRAÇÃO DA EDUCAÇÃO, 3., 2009, Vitória, Espírito Santo. Cadernos Anpae, n. 8, 2009.

PINTO, José Marcelino de Rezende. A política recente de fundos para o financiamento da educação e seus efeitos no pacto federativo. Educação \& Sociedade, Campinas, v. 28, n. 100, p. 877-897, out. 2007. 
PIRACICABA (SP). Lei no 5.081, de 19 de dezembro de 2001. Autoriza o município de Piracicaba a firmar convênio com entidades filantrópicas, ONGs e escolas particulares de educação infantil, objetivando o aumento da oferta de vagas, com a concessão de "bolsas creches" às crianças que não obtenham vagas na rede municipal e dá outras providências.

SILVEIRA, Adriana Aparecida D. Algumas considerações sobre as normas do processo de licitação pública, contratos e convênios no estabelecimento de parcerias educacionais entre a administração pública e a esfera privada. Educação: Teoria e Prática, Rio Claro (SP), v. 19, n. 32, p. 143-159, jan./jun. 2009. Disponível em: < http://www.periodicos.rc.biblioteca.unesp.br/index.php/educacao/ issue/view/777>.

Raquel Fontes Borghi, doutora em Educação Escolar pela Universidade Estadual Paulista Júlio de Mesquita Filho (Unesp), é professora Assistente do Departamento de Educação do Instituto de Biociências da Unesp/ Rio Claro e coordenadora do Grupo de Estudos e Pesquisas em Política Educacional (GREPPE), seção Rio Claro.

raborghi@gmail.com

Theresa Maria de Freitas Adrião, doutora em Educação pela Universidade de São Paulo, é professora da Faculdade de Educação da Universidade Estadual de Campinas (Unicamp) e coordenadora do Grupo de Estudos e Pesquisas em Política Educacional (GREPPE), seção Campinas. theadriao@gmail.com

Teise de Oliveira Guaranha Garcia, doutora em Educação pela Faculdade de Educação da Universidade de São Paulo, é professora da Faculdade de Filosofia, Ciências e Letras/USP de Ribeirão Preto e coordenadora do Grupo de Estudos e Pesquisas em Política Educacional (GREPPE), seção Ribeirão Preto.

teise@ffclrp.usp.br

Recebido em 24 de maio de 2010.

Aprovado em 25 de abril de 2011. 